\title{
Torta de girassol na alimentação de poedeiras semipesadas
}

\section{Sunflower cake in the diet of semi heavy weight laying hen}

\author{
João Waine Pinheiro ${ }^{1 *}$; Nilva Aparecida Nicolao Fonseca ${ }^{2}$; Caio Abércio da Silva ${ }^{1}$; \\ Alexandre Oba ${ }^{1}$; Mara Regina Stipp Balarin ${ }^{3}$; Sandra Regina Brunelli ${ }^{4}$
}

Resumo

Dois experimentos foram conduzidos com o objetivo de avaliar os efeitos da inclusão da torta de girassol na alimentação de galinhas poedeiras semi-pesadas. No Experimento 1 foram utilizadas duzentos e quarenta frangas da $10^{\mathrm{a}}$ até $16^{\mathrm{a}}$ semana de idade e peso médio inicial de $950,00 \pm 7,27 \mathrm{~g}$, distribuídas em quatro tratamentos experimentais com seis repetições cada, em grupos homogêneos de 10 aves, totalizando 60 frangas por tratamento, em um delineamento inteiramente casualizado. Os tratamentos experimentais consistiram de quatro rações isoproteicas e isocalóricas contendo 0 (controle), 7, 14, e $21 \%$ de inclusão de torta de girassol (TG). A utilização da TG não teve efeito $(\mathrm{P}>0,05)$ no ganho de peso, consumo de ração, conversão alimentar, comprimento do metatarso e triglicerídeos e colesterol séricos. No Experimento 2 cento e noventa e duas poedeiras, da $18^{\mathrm{a}}$ até $46^{\mathrm{a}}$ semana de idade, com peso médio corporal inicial de $1.700 \pm 29,40 \mathrm{~g}$, foram submetidas a quatro tratamentos experimentais com seis repetições cada, em grupos homogêneos de 8 aves, totalizando 48 galinhas por tratamento, em um delineamento inteiramente ao acaso. Os tratamentos experimentais consistiram de quatro rações contendo 0 (controle), 7, 14, e 21\% de inclusão TG. Não foram observados efeitos dos tratamentos $(\mathrm{P}>0,05)$ no desempenho produtivo, gravidade específica, porcentagem de casca e índice de pigmentação da gema do ovo. A inclusão de $21 \%$ TG reduziu significativamente $(\mathrm{P}<0,05)$ a unidade Haugh em relação ao controle $(0 \% \mathrm{TG})$. A torta de girassol pode compor $21 \%$ das rações de galinhas poedeiras semipesadas, sem efeitos adversos nos parâmetros produtivos.

Palavras-chave: Biodiesel, desenvolvimento corporal, desempenho produtivo, parâmetros sanguíneos, qualidade do ovo, qualidade nutricional

\begin{abstract}
This paper describes two experiments testing the effects of rations containing different sunflower meal (SFM) levels on laying hens' performance and egg quality. In the first experiment a total of 240 animals were divided in groups $(n=6)$ of 10 hens each, balanced by age and live weight and at random allocated to four isocaloric rations with $0,7,14$ and $21 \%$ of SFM. There was no effect $(\mathrm{P}>0.05)$ of SFM levels on hens' live weight, feed intake, feed conversion, metatarsus length, triglycerides and plasma cholesterol levels. In the second experiment a total of 192 animals were divided in groups $(n=6)$ of 8 hens each, balanced by age and live weight and at random allocated to four isocaloric rations with $0,7,14$ and $21 \%$ of SFM. There was no effect ( $\mathrm{P}>0.05)$ of SFM levels on eggs' production, specific gravity, percentage of shell and yolk color index. However, eggs of hens fed on $21 \%$ of SFM showed reduced $(\mathrm{P}<0.05)$
\end{abstract}

\footnotetext{
${ }^{1}$ Profs. Drs. do Dept ${ }^{\circ}$ de Zootecnia, Universidade Estadual de Londrina, UEL, Londrina, PR. E-mail:jwaine@uel.br; casilva@uel. br; oba@uel.br

${ }^{2}$ Prof $^{a}$ Dra $^{\mathrm{a}}$ Aposentada do Dept ${ }^{\mathrm{o}}$ de Zootecnia, UEL, Londrina, PR. E-mail: nilva@uel.br

${ }^{3}$ Prof $^{\mathrm{a}}$. Dra . do Dept ${ }^{\circ}$ Medicina Veterinária Preventiva, UEL, Londrina, PR. E-mail: maravet@uel.br

${ }^{4}$ Prof $^{\mathrm{a}} \mathrm{Dr}^{\mathrm{a}}$ do Curso de Medicina Veterinária, Faculdade de Ciências Sociais e Agrárias de Itapeva, FAIT, Itapeva, SP. E-mail: sandrareginabrunelli@hotmail.com

* Autor para correspondência
} 
Haugh units compared to eggs of animals fed on rations without SFM. These results indicate that there are no deleterious effects on performance and egg's quality of lying hens fed on rations containing up to $21 \%$ of SFM.

Key words: Biodiesel, body development, productive performance, blood parameters, egg quality, nutritional quality

\section{Introdução}

No Brasil os principais ingredientes utilizados no preparo das rações para poedeiras comerciais são o milho e o farelo de soja, cujos custos muitas vezes têm comprometido a economia da atividade sendo, portanto, constante a busca por ingredientes alternativos. A torta de girassol, obtida da prensagem a frio do grão do girassol, caracterizada como um produto com alta concentração de óleo, proteína e fibra (OLIVEIRA, 2003), tem determinado, quando participa da composição das dietas, melhora da palatabilidade, resultando em aumento no consumo, com repercussões positivas sobre a conversão alimentar e o efeito extra calórico, constituindo assim um potencial produto para o segmento.

A prensagem de $1000 \mathrm{~g}$ de grãos de girassol resulta aproximadamente $340 \mathrm{~g}$ de óleo e $660 \mathrm{~g}$ de torta com casca (SAN JUAN; VILLAMIDE, 2002), que possui características nutricionais intermediárias ao grão e ao farelo, constituindo um produto energético, de conteúdo proteico intermediário e elevado teor de fibra (SILVA et al., 2002).

Mcginnis, Hsu e Carver (1948), avaliando o uso de subprodutos do girassol na alimentação de aves, identificaram que a lisina constituía o primeiro aminoácido limitante no farelo, principalmente em pintos. Para a torta de girassol, obtida a partir do uso da prensa mecânica para a extração do óleo dos grãos, sem o uso de aquecimento, a limitação da lisina não se mostrou tão efetiva (HERKELMAN; CROMWELL, 1990).

O número de trabalhos que avaliaram a torta de girassol como um ingrediente das rações de aves é limitado. Fonseca et al. (2007), ao estudar níveis crescentes $(0,3,6,9$ e $12 \%)$ de torta de girassol em rações de frangos de corte dos 14 aos 35 dias e dos 36 aos 42 de idade, verificaram piora no ganho de peso e na conversão alimentar na primeira fase, mas não observaram comprometimento das características de desempenho na segunda fase, inferindo que os frangos em terminação são mais tolerantes à fibra da dieta.

Oliveira et al. (2010), verificaram que a inclusão de até $18 \%$ de uma torta de girassol com 26,06\% de proteína bruta, $18,57 \%$ de fibra bruta, 20,51\% de extrato etéreo e $3.000 \mathrm{kcalEM} / \mathrm{kg}$, nas rações de frangos de corte de 20 até 42 dias de idade não comprometeu os resultados zootécnicos, comparado com dietas a base de milho e farelo de soja, sugerindo a qualidade do ingrediente para aves mais velhas.

Considerando as características anatomofisiológicas do trato digestório, as poedeiras mostram-se mais tolerantes às concentrações elevadas de fibra na ração do que os frangos de corte. Em seus estudos Pinheiro et al. (1999) não encontraram alterações no crescimento de frangas de postura alimentadas com rações contendo até $21 \%$ de farelo de girassol, suplementadas ou não com lisina, atribuindo o êxito dos resultados às menores necessidades nutricionais destas aves na fase. Com poedeiras, Vieira et al. (1992) observaram que a inclusão crescente de farelo de girassol, entre 13 e $40,5 \%$, nas rações não resultaram efeitos negativos na produção e qualidade dos ovos, bem como no índice de mortalidade.

O presente estudo foi conduzido com o objetivo de avaliar os efeitos da inclusão da torta de girassol em rações de frangas e de poedeiras comerciais semipesadas, como ingrediente alimentar, sobre o crescimento, desempenho produtivo e a qualidade dos ovos. 


\section{Material e Métodos}

A torta de girassol (TG) utilizada no experimento foi obtida de uma indústria esmagadora do grão para a produção de biodiesel. Uma amostra foi analisada no Laboratório de Nutrição Animal (LANA) do departamento de Zootecnia da Universidade Estadual de Londrina, Pr, sendo determinado 93,51\% de matéria seca, $21,58 \%$ de proteína bruta, 26,55\% de extrato etéreo, $18,57 \%$ fibra bruta, $36,56 \%$ de fibra em detergente neutro e $26,26 \%$ de fibra em detergente ácido. No estudo de metabolismo foi determinado $3115 \mathrm{kcalEM} / \mathrm{kg}$ matéria natural.

Ao total foram utilizados 432 aves de uma linhagem de postura comercial semi-pesada, criadas entre 1 e 70 dias de idade em barracão de alvenaria, sobre cama de cepilho de madeira, com comedouros tubulares e bebedouros pendulares, sendo submetidas aos manejos de rotina. Aos 70 dias de idade foram transferidas para gaiolas apropriadas para a sua criação, definindo dois experimentos.

Experimento 1: Compreendeu o período entre o início da $10^{\mathrm{a}}$ semana e o final da $16^{\mathrm{a}}$ semana de idade. Foram utilizadas 240 frangas, com

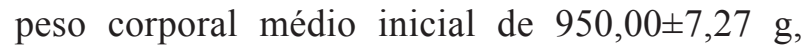
distribuídas em quatro tratamentos experimentais, em delineamento inteiramente casualizado, com seis repetições cada tratamento, constituído por grupos de 10 aves, homogêneos por peso, totalizando 60 frangas por tratamento. Estas aves foram alojadas em 24 gaiolas de arame galvanizado de $100 \mathrm{~cm}$ de comprimento (divididas em dois compartimentos de $50 \mathrm{~cm}$ ) x $50 \mathrm{~cm}$ profundidade x $50 \mathrm{~cm}$ de altura, localizadas em um barracão de recria de frangas. Adotou-se o programa de iluminação de 12 horas claro-escuro durante toda a fase experimental.

Os tratamentos experimentais consistiram de quatro rações (Tabela 1) contendo torta de girassol (TG), sendo um tratamento controle, sem inclusão de TG (0\%), e os demais com 7, 14, e $21 \%$ de TG. As rações foram formuladas a base de milho e farelo de soja de acordo com o programa alimentar recomendado para a linhagem. Os valores nutricionais dos alimentos utilizados, à exceção da TG, foram obtidos nas tabelas brasileiras (ROSTAGNO et al., 2005).

Ao final do experimento foram obtidos o consumo de ração, o ganho de peso, a conversão alimentar, o comprimento da canela e alguns parâmetros sanguíneos.

As rações fornecidas foram pesadas semanalmente, sendo as sobras determinadas ao final do experimento, obtendo-se a conversão alimentar, expressa em $\mathrm{kg}$ de ração/kg de ganho de peso $(\mathrm{kg} / \mathrm{kg})$.

O consumo de ração de cada ave, expresso em quilograma ( $\mathrm{kg} / \mathrm{ave})$, foi calculado dividindo-se o consumo de ração na parcela pelo número de aves. Nas parcelas que ocorreram mortes, dividiuse o consumo pela média ponderada de aves no período. 
Tabela 1. Composição e níveis nutricionais calculados das rações experimentais para frangas.

\begin{tabular}{|c|c|c|c|c|}
\hline \multirow{2}{*}{ Ingredientes (g/kg) } & \multicolumn{4}{|c|}{ Torta de Girassol (\%) } \\
\hline & 0 & 7 & 14 & 21 \\
\hline Milho & 684,59 & 637,87 & 591,17 & 544,45 \\
\hline Farelo soja & 218,07 & 191,80 & 165,52 & 139,25 \\
\hline Torta de girassol & 0,00 & 70,00 & 140,00 & 210,00 \\
\hline Farelo de trigo & 59,44 & 62,13 & 64,82 & 67,51 \\
\hline Fosfato bicálcico & 14,95 & 14,58 & 14,22 & 13,85 \\
\hline Calcário & 15,14 & 15,40 & 15,66 & 15,92 \\
\hline Sal & 3,00 & 3,00 & 3,00 & 3,00 \\
\hline DL-Metionina (99\%) & 0,30 & 0,20 & 0,10 & 0,00 \\
\hline L-Lisina $\mathrm{HCl}(79 \%)$ & 0,01 & 0,50 & 0,98 & 1,47 \\
\hline L-Triptofano (78\%) & 0,00 & 0,02 & 0,03 & 0,05 \\
\hline Suplemento vitamínico ${ }^{1}$ & 4,00 & 4,00 & 4,00 & 4,00 \\
\hline Suplemento mineral ${ }^{2}$ & 0,50 & 0,50 & 0,50 & 0,50 \\
\hline Total & 1000 & 1000 & 1000 & 1000 \\
\hline \multicolumn{5}{|l|}{ Exigências atendidas } \\
\hline Energia Metabolizável (kcal/kg) & 2.838 & 2.838 & 2.838 & 2.838 \\
\hline Proteína bruta $(\mathrm{g} / \mathrm{kg})$ & 168,0 & 168,0 & 168,0 & 168,0 \\
\hline Cálcio $(\mathrm{g} / \mathrm{kg})$ & 10,50 & 10,50 & 10,50 & 10,50 \\
\hline Fósforo disponível (g/kg) & 39,00 & 39,00 & 39,00 & 39,00 \\
\hline Lisina digestível $(\mathrm{g} / \mathrm{kg})$ & 7,20 & 7,20 & 7,20 & 7,20 \\
\hline Metionina digestível (g/kg) & 3,45 & 3,45 & 3,45 & 3,45 \\
\hline Triptofano digestível (g/kg) & 1,74 & 1,74 & 1,74 & 1,74 \\
\hline Fibra bruta $(\mathrm{g} / \mathrm{kg})$ & 31,60 & 42,36 & 53,14 & 63,91 \\
\hline Extrato etéreo $(\mathrm{g} / \mathrm{kg})$ & 28,70 & 45,40 & 62,09 & 78,80 \\
\hline
\end{tabular}

${ }^{1}$ Suplemento vitamínico por kg de produto: Vit. A 1.300 .000 UI; Vit. D3 450.000 UI; Vit. E 2.750 mg; Vit. K3 325 mg; Vit. B12 $2.500 \mathrm{mcg}$; Pantotenato de cálcio $2.000 \mathrm{mg}$; Biotina $4 \mathrm{mg}$; Niacina $6.000 \mathrm{mg}$; Piridoxina $425 \mathrm{mg}$; Riboflavina $875 \mathrm{mg}$; Tiamina $112,5 \mathrm{mg}$; Selênio 62,5 mg; Ácido fólico $50 \mathrm{mg}$; Colina 39,15 g ; Metionina 173,25 g; antioxidante $30.000 \mathrm{mg}$; Coccidiostático $100 \mathrm{~g}$; Promotor de crescimento $8.750 \mathrm{mg}$ e Veículo Q.S.P 1.000 g. ${ }^{2}$ Suplemento mineral por kg de produto: Cobre $18.000 \mathrm{mg}$; Zinco 120.000 mg; Iodo 2.000 mg; Ferro 60.000 mg; Manganês 120.000 mg e Veículo Q.S.P 1.000 g.

Fonte: Elaboração dos autores.

Ao final do experimento foram obtidos o consumo de ração, o ganho de peso, a conversão alimentar, o comprimento da canela e alguns parâmetros sanguíneos.

As rações fornecidas foram pesadas semanalmente, sendo as sobras determinadas ao final do experimento, obtendo-se a conversão alimentar, expressa em $\mathrm{kg}$ de ração/kg de ganho de peso $(\mathrm{kg} / \mathrm{kg})$.

O consumo de ração de cada ave, expresso em quilograma ( $\mathrm{kg} / \mathrm{ave}$ ), foi calculado dividindo-se o consumo de ração na parcela pelo número de aves. Nas parcelas que ocorreram mortes, dividiu-se o consumo pela média ponderada de aves no período.
As frangas de cada parcela foram pesadas em grupo, no inicio e no final do experimento, obtendose, por diferença, o ganho de peso, expresso em g/ ave.

Após a pesagem final, foi obtido o comprimento do metatarso esquerdo (do tornozelo até o coxim plantar) de duas frangas que apresentavam o peso médio da parcela, através de um paquímetro digital, tendo o seu valor expresso em $\mathrm{mm} / \mathrm{kg}$ de peso vivo $(\mathrm{mm} / \mathrm{kg}$ PV). Também foram obtidas amostras de sangue destas frangas, através da punção da veia braquial, para a determinação dos triglicerídeos e do colesterol séricos, expressos em mg/dL, utilizando kits laboratoriais. 
Experimento 2. Foram utilizadas 192 galinhas poedeiras com 18 semanas de idade inicial e peso corporal médio de $1.700 \pm 29,40 \mathrm{~g}$. O experimento teve a duração de 28 semanas, divididas em sete períodos de quatro semanas cada, encerrando às 46 semanas de idade. Foram estabelecidos quatro tratamentos experimentais, distribuídos em um delineamento inteiramente casualizado, com seis repetições de oito aves homogêneas em peso e porcentagem de postura, totalizando 48 aves por tratamento. Estas poedeiras foram alojadas em 24 gaiolas de arame galvanizado de $100 \mathrm{~cm}$ de comprimento (divididas em dois compartimentos de $50 \mathrm{~cm}$ ) x $45 \mathrm{~cm}$ profundidade $\mathrm{x}$ $40 \mathrm{~cm}$ de altura, quatro aves em cada compartimento, localizadas em um barracão de postura aberto. $\mathrm{O}$ programa de iluminação adotado foi o proposto no manual da linhagem.
Os tratamentos experimentais consistiram de quatro rações adicionadas com torta de girassol, sendo um tratamento controle, sem inclusão de TG $(0 \%)$ e os demais com 7, 14, e 21,0\% de TG (Tabela 2). As rações foram à base de milho e farelo de soja. Os valores nutricionais dos alimentos utilizados, à exceção da TG, e dsa exigências nutricionais foram obtidos nas tabelas brasileiras (ROSTAGNO et al., 2005).

Ao final do experimento foi avaliado o consumo de ração (g/ave/dia); produção de ovos (\%); peso médio dos ovos (g); massa de ovos (g/ave/dia) e conversão alimentar $(\mathrm{kg} / \mathrm{kg}$ e kg/dúzia).

A produção de ovos foi registrada diariamente, sendo que, após identificação, a produção em cada unidade experimental nos dois últimos dias de cada ciclo de 28 dias foi individualmente pesada.

Tabela 2. Composição e níveis nutricionais calculados das rações experimentais para poedeiras.

\begin{tabular}{|c|c|c|c|c|}
\hline \multirow{2}{*}{ Ingredientes (g/kg) } & \multicolumn{4}{|c|}{ Torta de girassol (\%) } \\
\hline & 0 & 7 & 14 & 21 \\
\hline Milho & 577,11 & 534,49 & 491,88 & 449,27 \\
\hline Farelo soja & 284,54 & 258,51 & 232,48 & 206,45 \\
\hline Torta de girassol & 0,00 & 70,00 & 140,00 & 210,00 \\
\hline Óleo vegetal & 25,13 & 23,48 & 21,83 & 20,19 \\
\hline Fosfato bicálcico & 16,20 & 15,86 & 15,52 & 15,17 \\
\hline Calcário & 90,88 & 91,13 & 91,38 & 91,64 \\
\hline Sal & 3,00 & 3,00 & 3,00 & 3,00 \\
\hline DL-Metionina (99\%) & 1,64 & 1,53 & 1,42 & 1,32 \\
\hline L-Lisina $\mathrm{HCl}(79 \%)$ & 0,00 & 0,48 & 0,96 & 1,45 \\
\hline Suplemento vitamínico ${ }^{1}$ & 1,00 & 1,00 & 1,00 & 1,00 \\
\hline Suplemento mineral ${ }^{2}$ & 0,50 & 0,50 & 0,50 & 0,50 \\
\hline Total & 1000,00 & 1000,00 & 1000,00 & 1000,00 \\
\hline \multicolumn{5}{|l|}{ Exigências atendidas } \\
\hline EM (kcal/kg) & 2.850 & 2850 & 2850 & 2850 \\
\hline Proteína bruta (g/kg) & 180,00 & 180,00 & 180,00 & 180,00 \\
\hline Cálcio $(\mathrm{g} / \mathrm{kg})$ & 40,00 & 40,00 & 40,00 & 40,00 \\
\hline Fósforo disponível (g/kg) & 4,00 & 4,00 & 4,00 & 4,00 \\
\hline Lisina digestível $(\mathrm{g} / \mathrm{kg})$ & 8,37 & 8,37 & 8,37 & 8,37 \\
\hline Metionina digestível (g/kg) & 4,20 & 4,20 & 4,20 & 4,20 \\
\hline Triptofano digestível (g/kg) & 1,94 & 1,94 & 1,94 & 1,94 \\
\hline Fibra bruta $(\mathrm{g} / \mathrm{kg})$ & 28,10 & 38,73 & 49,35 & 59,98 \\
\hline Extrato etéreo $(\mathrm{g} / \mathrm{kg})$ & 48,83 & 63,87 & 79,01 & 94,14 \\
\hline
\end{tabular}

${ }^{1}$ Suplemento vitamínico por kg de produto: Vit. A 8.000.000 UI; Vit. D3 2.300.000 UI; Vit. E 15.000 mg; Vit. K3 1.000 mg; Vit. B12 10.000 mcg; Pantotenato de cálcio 7.000 mg; Biotina 15 mg; Niacina 20.000 mg; Piridoxina 1.700 mg; Riboflavina 3.000 mg; Tiamina $200 \mathrm{mg}$; Ácido fólico $500 \mathrm{mg}$; Selênio $250 \mathrm{mg}$; antioxidante $30.000 \mathrm{mg}$ e Veículo Q.S.P 1.000 g. ${ }^{2}$ Suplemento mineral por kg de produto: Cobre $18.000 \mathrm{mg}$; Zinco $120.000 \mathrm{mg}$; Iodo $2.000 \mathrm{mg}$; Ferro $60.000 \mathrm{mg}$; Manganês $120.000 \mathrm{mg}$ e Veículo Q.S.P $1.000 \mathrm{~g}$.

Fonte: Elaboração dos autores. 
Dois ovos com peso médio da parcela foram submetidos aos estudos da sua qualidade interna e externa através da determinação da gravidade específica $\left(\mathrm{g} / \mathrm{cm}^{3}\right)$, unidade Haugh (UH), porcentagem de casca (\%) e cor da gema. A gravidade específica foi determinada segundo a metodologia descrita por Freitas et al. (2004). $\mathrm{Na}$ sequência os ovos foram quebrados e sobre uma mesa de vidro foi determinada a altura da clara, através de um micrometro digital, próximo da gema e perpendicular à chalaza, obtendo-se os valores de unidade Haugh, através da fórmula sugerida por Stadelman e Cotteril (1986). Foi obtido também o valor do índice de pigmentação da gema, através do leque colorimétrico (Roche). As cascas identificadas, após lavagem em água e expostas por 72 horas à temperatura ambiente, foram pesadas e correlacionadas percentualmente com o peso do ovo.

Os dados obtidos nos dois experimentos foram submetidos à análise de variância utilizando o programa STATISTICA 10, considerando o nível de inclusão da torta de girassol como variável independente. Na comparação das médias para cada nível de inclusão de torta de girassol, em relação à testemunha, utilizou-se o teste de Dunnett $(5 \%)$. Posteriormente, excluindo-se a ração controle $(0 \%$ TG), a soma de quadrado referente aos efeitos da inclusão da torta de girassol com efeito significativo foi decomposta em polinômios para determinar a curva que melhor descrevesse o comportamento dos dados e na escolha do modelo de regressão foi considerado o nível de significância e o coeficiente de determinação $\left(\mathrm{R}^{2}\right)$.

\section{Resultados e Discussão}

Experimento 1: Os níveis de inclusão de TG (7, 14 e $21 \%$ ) na ração das frangas resultaram valores de desempenho semelhantes $(\mathrm{P}>0,05)$ aos da ração controle (Tabela 3 ), sendo as médias obtidas condizentes com as estabelecidas no manual de criação da linhagem.

Tabela 3. Ganho de peso (GP), consumo de ração (CR), conversão alimentar (CA), comprimento do metatarso (CM), triglicerídeo (TG), colesterol (CL) de acordo com os tratamentos.

\begin{tabular}{|c|c|c|c|c|c|c|c|}
\hline \multirow{2}{*}{ Variável } & \multicolumn{4}{|c|}{ Torta de Girassol (\%) } & \multirow{2}{*}{ Média } & \multirow{2}{*}{$\mathrm{P}(<\mathrm{F})^{1}$} & \multirow{2}{*}{$\mathrm{CV}(\%)^{2}$} \\
\hline & 0 & 7 & 14 & 21 & & & \\
\hline GP (kg/ave) & $0,583 \pm 0,022$ & $0,575 \pm 0,015$ & $0,58 \pm 0,015$ & $0,59 \pm 0,029$ & 0,58 & 0,745 & 3,66 \\
\hline CR (kg/ave) & $3,078 \pm 0,245$ & $2,96 \pm 0,113$ & $3,07 \pm 0,044$ & $3,06 \pm 0,054$ & 3,04 & 0,441 & 4,59 \\
\hline $\mathrm{CA}(\mathrm{kg} / \mathrm{kg})$ & $5,286 \pm 0,515$ & $5,145 \pm 0,137$ & $5,29 \pm 0,290$ & $5,21 \pm 0,184$ & 5,23 & 0,812 & 5,75 \\
\hline $\mathrm{CM}(\mathrm{mm} / \mathrm{kgPV})$ & $64,36 \pm 3,04$ & $65,10 \pm 1,86$ & $64,58 \pm 2,14$ & $65,26 \pm 2,78$ & 64,83 & 0,914 & 3,86 \\
\hline $\mathrm{TG}(\mathrm{mg} / \mathrm{dL})$ & $95,83 \pm 18,70$ & $106,50 \pm 11,43$ & $112,17 \pm 26,08$ & $110,80 \pm 10,98$ & 106,3 & 0,402 & 16,83 \\
\hline CL (mg/dL) & $113,00 \pm 13,61$ & $112,50 \pm 12,13$ & $122,00 \pm 26,00$ & $119,50 \pm 12,77$ & 116,7 & 0,714 & 14,66 \\
\hline
\end{tabular}

${ }^{1} \mathrm{P}(<\mathrm{F})$ significância pelo teste de $\mathrm{F} ;{ }^{2} \mathrm{CV}(\%)$ Coeficiente de variação; \pm desvio padrão da média.

Fonte: Elaboração dos autores.

Houve semelhança $(\mathrm{P}>0,05)$ entre os consumos de ração para os tratamentos experimentais, não sendo evidenciados efeitos das elevadas concentrações dietéticas de fibra das rações que continham TG no desenvolvimento das frangas. Preservadas as características dos ingredientes utilizados nos trabalhos, os resultados obtidos foram semelhantes aos de Mitchel e Sunde (1985), que ao substituírem totalmente o farelo de soja na ração das frangas por grãos de girassol também não encontraram alterações no consumo. Togun, Farinu e Olabanji (2006) enfatizaram que, devido à alta concentração de fibras, rações com mais de $20 \%$ de inclusão de farelo de girassol proporcionaram 
menores consumos e menores ganhos de pesos em frangas de postura semipesadas, chamando a atenção da necessidade de uma adaptação das aves a este alimento para que possa ocorrer maior consumo e utilização. Ekeocha e Afolabi (2012) atribuíram à palatabilidade o menor consumo de ração dos frangos de corte alimentados com rações contendo girassol.

A adição de alimentos fibrosos nas rações evita que as poedeiras tenham ganhos de pesos excessivos, principalmente nas linhagens que apresentam maior capacidade ingestiva (SCHEIDELER; JARONI; FRONING, 1998), como a utilizada neste experimento. Fonseca et al. (2007) notaram que o aumento da fibra bruta dietética, decorrente das inclusões crescentes de torta de girassol na ração, constituiu-se fator limitador ao desenvolvimento de frangos de corte com até os 35 dias de idade. Contudo, Pinheiro et al. (1999) indicaram que a inclusão de $21 \%$ de farelo de girassol, também rico em fibra, pode ser adotado para frangas de postura de linhagem leve em crescimento, de 12 até 20 semanas de idade, sem prejuízos ao desempenho, sugerindo maior tolerância destas aves à rações mais fibrosas.

Não foram verificadas diferenças entre os comprimentos dos metatarsos $(\mathrm{P}>0,05)$ em decorrência dos tratamentos experimentais. A formação e o desenvolvimento dos tecidos ósseos nas frangas constituem fatores importantes para o desempenho da futura poedeira, sendo a fase de
7 a 12 semanas de vida a de maior crescimento e formação do esqueleto. Wilson et al. (1995), consideraram que o comprimento do metatarso é um bom indicador do desenvolvimento esquelético das frangas, afirmação reiterada por Moreki (2005), para quem as aves mais pesadas e com maior taxa de crescimento apresentam maior comprimento do tarso-metatarso.

Apesar das elevações nas concentrações dietéticas de extrato etéreo para as inclusões de TG, estas não ocasionaram efeitos significativas $(\mathrm{P}>0,05)$ nas concentrações dos triglicérides séricos, frente a ração controle ( $0 \% \mathrm{TG})$. Os valores dos parâmetros bioquímicos séricos das aves estão intimamente relacionados ao desempenho produtivo e às doenças metabólicas. A síndrome do fígado e de rins gordurosos está relacionada com o metabolismo de colesterol (FUDGE, 1996). A ocorrência de gordura abdominal está ligada ao metabolismo lipídico (HERMIER， 1997; CORNEJO; GADELHA; VILLOUTA, 2007).

Comparando as médias dos parâmetros bioquímicos sanguíneos estudados com os valores de referencia para frangos de corte, os triglicerídeos se mostraram elevados (EVANS et al., 1977) e o colesterol normal (ROSS et. al., 1978).

Experimento 2: Os parâmetros de desempenho das poedeiras não evidenciaram efeitos $(\mathrm{P}>0,05)$ das inclusões de TG (7, 14 e 21\%), frente ao tratamento controle (Tabela 4). 
Tabela 4. Consumo de ração (CR), porcentagem de postura (PT), peso do ovo (PO), massa de ovo (MO), conversão alimentar $(\mathrm{CA} \mathrm{kg} / \mathrm{kg})$, conversão alimentar $(\mathrm{CA} \mathrm{kg} / \mathrm{dz})$, gravidade específica $(\mathrm{GE})$, unidade Haugh $(\mathrm{uH})$, porcentagem de casca (PC), coloração da gema (CG) de acordo com os tratamentos.

\begin{tabular}{|c|c|c|c|c|c|c|c|}
\hline \multirow{2}{*}{ Desempenho } & \multicolumn{4}{|c|}{ Torta de Girassol (\%) } & \multirow{2}{*}{ Média } & \multirow{2}{*}{$\mathrm{P}(<\mathrm{F})^{1}$} & \multirow{2}{*}{$\mathrm{CV}(\%)^{2}$} \\
\hline & 0 & 7 & 14 & 21 & & & \\
\hline CR (g/ave/dia) & $114,59 \pm 10,63$ & $112,23 \pm 10,07$ & $109,48 \pm 9,15$ & $110,02 \pm 11,23$ & 111,58 & 0,095 & 9,23 \\
\hline PT $(\%)$ & $86,75 \pm 16,10$ & $88,20 \pm 17,04$ & $90,18 \pm 9,98$ & $87,54 \pm 15,45$ & 88,16 & 0,777 & 17,68 \\
\hline $\mathrm{PO}(\mathrm{g})$ & $64,21 \pm 4,65$ & $63,39 \pm 4,22$ & $62,91 \pm 4,47$ & $62,86 \pm 4,97$ & 63,34 & 0,510 & 7,21 \\
\hline MO (g/ave/dia) & $56,30 \pm 12,73$ & $56,46 \pm 12,77$ & $57,20 \pm 11,21$ & $55,46 \pm 11,80$ & 56,35 & 0,932 & 21,38 \\
\hline $\mathrm{CA}(\mathrm{kg} / \mathrm{kg})$ & $2,17 \pm 0,65$ & $2,13 \pm 0,70$ & $2,00 \pm 0,47$ & $2,09 \pm 0,56$ & 2,10 & 0,603 & 28,67 \\
\hline $\mathrm{CA}(\mathrm{kg} / \mathrm{dz})$ & $1,64 \pm 0,35$ & $1,60 \pm 0,39$ & $1,49 \pm 0,25$ & $1,55 \pm 0,30$ & 1,57 & 0,182 & 21,02 \\
\hline \multicolumn{8}{|l|}{ Qualidade do ovo } \\
\hline $\mathrm{GE}\left(\mathrm{g} / \mathrm{cm}^{3}\right)$ & $1,094 \pm 0,007$ & $1,096 \pm 0,009$ & $1,094 \pm 0,008$ & $1,094 \pm 0,008$ & 1,095 & 0,605 & 0,74 \\
\hline $\mathrm{UH}(\mathrm{uH})$ & $80,30 \pm 4,45$ & $81,02 \pm 5,83$ & $80,63 \pm 5,71$ & $76,23 \pm 6,31^{*}$ & 79,82 & 0,0003 & 7,13 \\
\hline PC (\%) & $9,91 \pm 0,49$ & $10,07 \pm 0,45$ & $9,86 \pm 0,53$ & $9,99 \pm 0,37$ & 9,95 & 0,169 & 4,66 \\
\hline $\mathrm{CG}$ & $4,42 \pm 0,65$ & $4,20 \pm 0,38$ & $4,30 \pm 0,38$ & $3,37 \pm 0,63$ & 4,32 & 0,227 & 12,15 \\
\hline
\end{tabular}

"Médias ( \pm desvio padrão) distintas na mesma linha diferem da ração testemunha $\left(0 \%\right.$ TG) pelo teste de Dunnett $(5 \%) ;{ }^{1} \mathrm{P}(<\mathrm{F})$ Significância pelo teste de F; ${ }^{2} \mathrm{CV}(\%)$ Coeficiente de Variação; \pm desvio padrão da média.

Fonte: Elaboração dos autores.

Quanto ao consumo de ração, considerando as características dos alimentos, os resultados se assemelharam aos de Senkoylu, Akyurek e Samli (2004) e de Sayda, Hyder e Abasaid, (2011), que também ao estudarem inclusões crescentes de um farelo gordo de girassol de alta fibra na ração de poedeiras também não encontraram diferenças entre as médias.

Existem controversas sobre os efeitos da fibra do girassol no consumo de ração em aves. Jacob et al. (1996) e Rezaei e Hafezian (2007) verificaram, respectivamente, que galinhas poedeiras alimentadas com rações contendo grãos ou farelo de girassol apresentaram redução na ingestão de alimento. $\mathrm{O}$ que se explicaria pela elevada fibra contida no produto que, além de alterar a densidade da ração, aumenta a capacidade relativa da digesta em absorver água (RODRÍGUEZ-PALENZUELA; GARCIA; DE BLAS, 1998; PANIGRAHI, 1992), ocupando maior espaço no trato digestório, ocasionando distensão gástrica. Neste processo os mecanoreceptores localizados no papo e na moela sinalizariam ao sistema nervoso central, via nervo vago, o término da refeição (SAVORY, 1985). Em sentido contrário, em seus estudos Vieira et al. (1992) observaram que poedeiras semipesadas alimentadas com rações contendo entre 13,5 e 40,5\% de farelo de girassol apresentaram aumento no consumo, o que atribuíram à baixa energia decorrente do alimento.

As inclusões de TG não influenciaram o peso dos ovos. Karunajeewa, Tham e Abu-Serewa (1989), Senkoylu, Akyurek e Samli (2004) e Casartelli et al. (2006) também observaram semelhanças entre produção, peso e massa dos ovos para os níveis crescentes de farelo de girassol na ração de galinhas poedeiras.

Além de grande variação na composição química, aliada ao alto conteúdo de fibra, a baixa concentração de lisina existente no farelo e na torta de girassol pode se caracterizar como fator restritivo dos seus usos em rações de aves (SENKOYLU; DALE, 1999). Rezaei e Hafezian (2007) relacionaram a redução do peso dos ovos à baixa digestibilidade dos aminoácidos do farelo de girassol, contradizendo Vieira et al. (1992) que demostraram efeitos positivos da inclusão de até $26 \%$ de farelo de girassol no peso médio dos ovos, independente da inclusão ou não de lisina. Estudando tipos de grãos e fontes de proteína na alimentação de poedeiras, 
Jacob et al. (1996) verificaram redução na produção de ovos para rações com 13,3\% de grãos de girassol moídos, sem especificar as causas determinantes.

No presente estudo as inclusões de TG nas rações exigiram suplementações crescentes de lisina a fim de suprir possíveis deficiências do aminoácido, o que pode ter influenciado a ausência de efeitos dos tratamentos no peso e na massa de ovos.

As médias de conversão alimentar $(\mathrm{kg} / \mathrm{kg}$ e $\mathrm{kg} /$ $\mathrm{dz}$ ) foram semelhantes $(\mathrm{P}>0,05)$ para os tratamentos experimentais. Casartelli et al. (2006) também não encontraram efeitos da inclusão crescente $(0,4$, 8 e $12 \%$ ) do farelo de girassol sobre conversão alimentar de poedeiras, evidenciando a capacidade destas aves em transformar alimentos fibrosos em ovos. No entanto os resultados dos trabalhos conduzidos por Karunajeewa, Tham e Abu-Serewa (1989), Vieira et al. (1992), Jacob et al. (1996), Senkoylu, Akyurek e Samli (2004) contrariam este resultado ao demonstrarem piora na conversão alimentar das poedeiras alimentadas com rações contendo inclusões crescentes de farelo de girassol, o que atribuíram a alta fibra e à baixa digestibilidade dos aminoácidos (REZAEI; HAFEZIAN, 2007), fatores ligados à produção e massa dos ovos.

A gravidade específica, a porcentagem de casca e a pigmentação da gema dos ovos das poedeiras submetidas aos tratamentos contendo $\mathrm{TG}$ foram semelhantes $(\mathrm{P}>0,05)$ ao controle. Os trabalhos de Casartelli et al. (2006) determinaram efeito linear crescente das inclusões de farelo de girassol $(0,4$, 8 e 12\%) na gravidade específica e efeito cúbico na porcentagem de casca dos ovos. Karunajeewa, Tham e Abu-Serewa (1989), Vieira et al. (1992), Tsuzuki et al. (2003), Rezaei e Hafezian (2007) e Sayda, Hyder e Abasaid (2011) evidenciaram semelhanças entre as intensidades de cor das gemas para as diferentes inclusões de girassol nas rações.

A intensidade da cor amarela da gema é resultado da capacidade de deposição e de pigmentação da xantofila. O milho, por conter alta concentração de luteína, ao ser substituído por outro ingrediente na ração das poedeiras pode ocasionar gemas menos amarelas (UWAYJAN; AZAR; DAGHIR, 1983). O que foi confirmado por Rowghani, Maddahian e Abousadi, (2006), que obtiveram gemas menos amarelas nas poedeiras alimentadas com rações contendo $43 \%$ de farelo de trigo, $19 \%$ de milho e $8 \%$ de farelo de girassol, coloração esta revertida pelo uso de pigmentantes artificiais. Uwayjan, Azar e Daghir (1983) também encontraram gemas menos amarelas nas gemas de poedeiras alimentadas com rações contendo $30 \%$ de grãos de girassol. As borras de óleos vegetais, normalmente utilizadas na ração de aves como fonte de energia, são ricas em pigmentos amarelos. No entanto, Pardio et al. (2001) verificaram baixa concentração do pigmento xantofila na borra de óleo de girassol, quando comparada com a do óleo de soja e do óleo do milho, atribuindo a este componente a menor pigmentação amarela da pele dos frangos. A ração com $21 \% \mathrm{TG}$ utilizada neste experimento continha menos milho e mais óleo de girassol na sua formulação, podendo ser esta a explicação para a redução não significativa da intensidade de cor das gemas deste tratamento.

Comparado ao controle, o tratamento com 21\% de TG ocasionou redução $(\mathrm{P}<0,05)$ na unidade Haugh $(\mathrm{uH})$. Excluindo o tratamento controle, observou-se resposta linear decrescente para a unidade Haugh, $\mathrm{Y}_{\mathrm{uH}=} 86,17-0,456^{* *} \mathrm{X}(\mathrm{SEE}=5,79 ; \mathrm{r}$ $=-0,4135 ; \mathrm{P}(<\mathrm{F}) \beta_{1}=0,0001 ; \mathrm{R}^{2}=17,10$. De forma geral, quanto menor o valor da unidade Haugh, pior é a qualidade interna do ovo (RODRIGUES, 1975).

Karunajeewa, Tham e Abu-Serewa (1989) atribuíram aos fatores antinutricionais termolábeis presentes nos grãos de girassol a diminuição dos valores de unidade Haugh dos ovos. Dagbir, Rad e Uwadvjan (1980) também atribuíram a estes fatores o menor crescimento de frangos de corte alimentados com rações contendo $30 \%$ de grãos de girassol. O grão do girassol possui vários fatores antinutricionais, sendo ócido clorogênico o demaior ocorrência, que pode influenciar negativamente no metabolismo da proteína e na disponibilidade da lisina (BRENES; JANSMAN; MARQUARDT, 
2004). A presença de antinutrientes na torta de girassol pode ter sido o fator determinante para a redução índice de uH dos ovos deste experimento.

\section{Conclusões}

Apesar de proporcionar redução da unidade Haugh, importante atributo indicativo da qualidade interna do ovo, a torta de girassol se mostrou um alimento passível de compor $21 \%$ da ração das galinhas poedeiras semipesadas.

\section{Referências}

BRENES, A.; JANSMAN, A. J. M.; MARQUARDT, R. R. Recent progress on research on the effects of antinutritional factors in legume and oil seeds in monogastric animals. In: Recent advances of research in antinutritional factors in legume seeds and oil seeds, 2004, Toledo. Anais... Toledo, Espanha: EAAP, 2004. p. 195-218.

CASARTELLI, E. M.; FILARDI, R. S.; JUNQUERIA, O. M.; LAURENTZ, A. C.; ASSUENA, V.; DUARTE, $\mathrm{K}$.F. Inclusion levels of sunflower meal in commercial laying hen diets formulated on total and digestible amino acids basis. Revista Brasileira de Ciências Avícolas, Campinas, v. 8, n. 3, p. 151-155, 2006.

CORNEJO, S.; GADElHA, A. C.; VILlOUTA, G. Qualitative feed restriction on productive performance and lipid metabolism in broiler chickens. Arquivos Brasileiros de Medicina Veterinária e Zootecnia, Belo Horizonte, v. 59, n. 6, p. 1554-1562, 2007.

DAGBIR, N. J.; RAD, M. A.; UWADVJAN, M. Studies on utilization of full fat sunflower seed in broiler ration. Poultry Science, Champaign, v. 59, n. 10, p. 2273-2278, 1980.

EKEOCHA, A. H.; AFOLABI, K. D. Carcass characteristics of broilers fed Mexican sunflower (Tithonia diversifolia) leaf meal-based diets. Journal of Animal Production Advances, Shabestar Branch, v. 2, n. 5, p. 271-276, 2012.

EVANS, A. J.; BANNISTER, D. W.; WHITEHEAD, C. C.; SILLE, W. G.; WIGHT, P. A. Changes in plasma lipid and glucose levels during the onset of fatty liver and kidney syndrome in chicks. Research in Veterinary Science, Roma, v. 23, n. 3, p. 275-279, 1977.

FONSECA, N. A. N.; PINHEIRO, J. W.; BRUNELLI, S. R.; SILVA, C. A.; SAZAKA, J. H. Torta de girassol na alimentação de frangos de corte. In: ZOOTEC 2007, Londrina. Anais... Londrina: ABZ, Associação Brasileira de Zootecnistas, 2007. CD-ROM.

FREITAS, E. R.; SAKOMURA, N. K.; GONZALEZ, M. M.; BARBOSA, N. N. A. Comparação de métodos de determinação da gravidade específica de ovos de poedeiras comerciais. Pesquisa Agropecuária Brasileira, Brasília, v. 39, n. 5, p. 509-512, 2004.

FUDGE, A. M. Avian clinical biochemistry. In: ROSSKOPF JUNIOR, W. J.; WOERPEL, R. W. Disease of cage and aviary birds. $3^{\text {rd }}$ ed. Williams \& Wilkins, Baltimore. 1996. p.773-794.

HERKELMAN, K. L.; CROMWELL, A. G. Utilization of full fat soybean by swine reviewed. Feedstuffs, Bloomington, v. 62, n. 1, p. 13-22, 1990.

HERMIER, D. Lipoprotein metabolism and fattening in poultry. Conference: avian lipoprotein metabolism: an update. The Journal of Nutrition, Bethesda, v. 127, n. 5, p. 805S-808S, 1997.

JACOB, J. P.; MITARU, B. N.; MBUGUA, P. N.; BLAIR, R. The feeding value of kenyan sorghum, sunflower seed cake and sesame seed cake for broilers and layers. Animal Feed Science and Technology, Davis, v. 61, n. 1-4, p. 41-56, 1996.

KARUNAJEEWA, H.; THAM, S. H.; ABU-SEREWA, S. Sunflower seed meal, sunflower oil and full-fat sunflower seeds, hulls and kernels for laying hens. Animal Feed Science and Technology, Davis, v. 26, n. 1-2, p. 45-49, 1989.

MCGINNIS, J.; HSU, P. T.; CARVER, J. S. Nutritional deficiencies of sunflower seed oil meal for chicks. Poultry Science, Champaign, v. 27, n. 4, p. 389-393, 1948.

MITCHEL, J. N.; SUNDE, M. L. Sunflower meal in pullet developer diets. Poultry Science, Champaign, v. 64, n. 4, p. 669-674, 1985.

MOREKI, J. C. The influence of calcium intake by broiler breeders on bone development and egg characteristics. 2005. Thesis Philosophiae Doctor (Ph.D.) - University of the Free State, Bloemfontein, Republic of South Africa.

OLIVEIRA, D. D.; PINHEIRO, J. W.; FONSECA, N. A. N.; OBA, A.; SILVEIRA, D. F.; STIVALETTI, E. L. T. Desempenho de frangos de corte alimentados com torta de girassol. In: REUNIÃO ANUAL DA SOCIEDADE BRASILEIRA DE ZOOTECNIA, 47., 2010, Salvador. Anais... Salvador: SBZ, Sociedade Brasileira de Zootecnia, 2010. CD-ROM.

OLIVEIRA, M. D. S. Torta da prensagem a frio na alimentação de bovinos. In: SIMPÓSIO NACIONAL 
E REUNIÃO NACIONAL DA CULTURA DE GIRASSOL, 3., 2003, Ribeirão Preto. Anais... Ribeirão Preto: CATI, 2003. CD-ROM.

PANIGRAHI, S. Effects of different copra meals and amino acid supplementation on broiler chick growth. British Poultry Science, London, v. 33, n. 3, p. 683-687, 1992.

PARDIO, V. T.; LANDIN, L. A.; WALISZEWSKI, K. N.; BADILLO, C.; PEREZ-GIL, F. The effect of acidified soapstocks on feed conversion and broiler skin pigmentation. Poultry Science, Champaign, v. 80, n. 8, p. 1236-1239, 2001.

PINHEIRO, J. W.; FONSECA, N. A. N.; CABRERA, L.; SUGETA, S. M.; OTUTUMI, L. K.; UENO, P. M. Uso de rações contendo diferentes níveis de farelo de girassol e lisina na alimentação de frangas de postura de 6 a 18 semanas de idade. In: REUNIÃO ANUAL DA SBZ, 47., 1999, Porto Alegre. Anais... Porto Alegre: SBZ, Sociedade Brasileira de Zootecnia, 1999. CD-ROM.

REZAEI, M.; HAFEZIAN, H. Use of different levels of high fiber sunflower meal in commercial leghorn type layer diets. International Journal of Poultry Science, Faisalabad, v. 6, n. 6, p. 431-433, 2007.

RODRIGUES, P. C. Contribuição ao estudo da conversão de ovos de casca branca e vermelha. 1975. Dissertação (Mestrado em Ciência Animal e Pastagens) - Escola Superior de Agricultura Luiz de Queiroz. Universidade de São Paulo, Piracicaba.

RODRÍGUEZ-PALENZUELA， P.; GARCIA， J.; DE BLAS, C. Fibra soluble y su implicación en nutrición animal: enzimas y probióticos. In: CURSO DE ESPECIALIZACIÓN FEDNA: AVANCES EN NUTRICIÓN Y ALIMENTACIÓN ANIMAL, 14., 1998, Barcelona. Anais.... Barcelona: FEDNA, 1998. p. 227-240.

ROSS, J. G.; CHRISTIE, G.; HALLIDAYM, W. G. F.; MORLEY JONES, R. Hematological and blood chemistry "comparison values" for clinical pathology in poultry. Veterinary Record, London, v. 102, n. 2, p. 2931, 1978.

ROSTAGNO, H. S.; ALBINO, L. F. T.; DONZELE, J. L.; GOMES, P. C.; OLIVEIRA, R. F.; LOPES, D. C.; FERREIRA, A. S.; BARRETO, S. L. T. Tabelas brasileiras para aves e suínos: composição de alimentos e exigências nutricionais. 2. ed. Viçosa, MG: Universidade Federal de Viçosa, 2005. 186 p.

ROWGHANI, E.; MADDAHIAN, A.; ABOUSADI, M. A. Effects of addition of marigold flower, safflower petals, red pepper on egg-yolk color and egg production in laying hens. Pakistan Journal of Biological Sciences, v. 9, n. 7, p. 1333-1337, 2006.
SAN JUAN, L. D.; VILLAMIDE, M. J. Nutritional evaluation of sunflower seed and products derived from them. Effect of oil extraction. British Poultry Science, London, v. 41, n. 2, p. 182-192, 2000.

SAVORY, C. J. An investigation into the role of the crop of feeding in Japanese quail and domestic fowls. Physiology \& Behavior, Cincinnati, v. 35, n. 6, p. 917928, 1985.

SAYDA, A. M. A.; HYDER, O. A.; ABASAID, M. A. Sunflower meal as an alternative protein source to groundnut meal in laying hens ration. Egyptian Poultry Science, Alexandria, v. 31, n. 4, p. 745-753, 2011.

SCHEIDELER, S. E.; JARONI, D.; FRONING, G. Strain and age effects on egg composition from hens fed diets rich in $\mathrm{n}-3$ fatty acids. Poultry Science, Champaign, v. 77, n. 2, p. 192-196, 1998.

SENKOYLU, N.; AKYUREK, H.; SAMLI, H. E. The possibilities of using high oil-sunflower meal and enzyme mixture in layer diets. Pakistan Journal of Nutrition, Faisalabad, v. 3, n. 5, p. 285-289, 2004.

SENKOYLU, N.; DALE, N. Sunflower meal in poultry diets. World's Poultry Science Journal, Cambridge, v. 55, n. 2, p. 153-174, 1999.

SILVA, C. A.; PINHEIRO, J. W.; FONSECA, N. A. N.; SARUBBI, J.; COSTA, M. C. R.; PACHECO, G. D.;TELLES, H.; HEDESHIMA, C. S.; MOURINHO, F. L.; BOROSKI, J. C. Digestibilidade da torta de girassol para suínos na fase de crescimento. In: CONGRESSO LATINO AMERICANO DE SUINOCULTURA, 1., 2002, Foz do Iguaçu. Anais... Foz do Iguaçu: EMBRAPA Suínos e Aves, 2002. p. 219-220.

STADELMAN, W. J.; COTTERIL, O. J. Egg science and technology. 3. ed. New York: Food Products Press, 1986. $499 \mathrm{p}$.

TOGUN, V. A.; FARINU, G. O.; OLABANJI, R. O. Feeding graded levels of wild sunflower (Tithonia diversifolia Hemsl. A. Gray) meal in replacement of maize at pre-pubertal age, negatively impacts on growth and morphormetric characteristics of the genitalia of anak 2000 broiler cocks at their pubertal age. World Applied Sciences Journal, Dubai, v. 1, n. 2, p. 115-121, 2006.

TSUZUKI, E. T.; GARCIA, E. R. M.; MURAKAMI, A. E.; SAKAMOTO, M. Utilization of sunflower seed in laying hen rations. Revista Brasileira de Ciência Avícola, Campinas, v. 5, n. 3, p. 179-182, 2003.

UWAYJAN, M. G.; AZAR, E. J.; DAGHIR, N. J. Sunflower seed in laying hen rations. Poultry Science, Champaign, v. 62, n. 7, p. 1247-1253, 1983. 
VIEIRA, S. L.; PENZ JUNIOR, A.M.; LE BOUTE, WILSON, J. L.; ROBINSON, E. E.; ROBINSON, N. E. M.; CORTELINE, J. A. Nutritional evaluation of a A.; HARDIN, R. T. Effects of feed allocation on female high fiber sunflower meal. Journal of Applied Poultry Research, Champaign, v. 1, n. 4, p. 382-388, 1992. broiler breeders. Journal of Applied Poultry Research, Champaign, v. 4, n. 2, p. 193-202, 1995. 